\title{
SRAP analysis of DNA base sequence changes in lotus mutants induced by $\mathrm{Fe}^{+}$implantation
}

\author{
C.L. Deng, R.Y. Qin, J. Gao, Y.Y. Jia, Y.X. Ren, W.J. Gao and L.D. Lu \\ College of Life Science, Henan Normal University, Xinxiang, China \\ Corresponding author: C.L. Deng \\ E-mail: dc175@yahoo.cn
}

Genet. Mol. Res. 12 (1): 335-343 (2013)

Received April 14, 2012

Accepted August 2, 2012

Published February 7, 2013

DOI http://dx.doi.org/10.4238/2013.February.7.3

\begin{abstract}
Ion implantation, a new biophysically mutagenic technique, has shown great potential for crop breeding. To reveal the mutation effect of low-energy ion implantation on Baiyangdian red lotus, sequence-related amplified polymorphism markers were used to amplify and detect the DNA sequence differences in mutants induced by $\mathrm{Fe}^{+}$ion implantation. A total of 121 primer combinations were tested in 6 mutants and a control. Seven primer combinations (me1 $+\mathrm{em} 3$, $\mathrm{me} 1+\mathrm{em} 14, \mathrm{me} 9+\mathrm{em} 3, \mathrm{me} 8+\mathrm{em} 2, \mathrm{me} 6+\mathrm{em} 1, \mathrm{me} 11+\mathrm{em} 5$, and me6 + em5) generated clear bands with high polymorphism and good repeatability. The results showed that among 15,317 bases cloned, 146 bases in 6 mutants were different from those of the wild type, showing a variation frequency of $0.95 \%$. The types of base changes included deletion, insertion, transversion, and transition. Adenine was more sensitive to the irradiation than were the other bases. The results suggested that mutational "hotspots" probably exists in lotus and are induced by low-energy ion implantation.
\end{abstract}

Key words: Baiyangdian red lotus; Ion implantation; SRAP marker; Specific fragment; Sequence analysis 


\section{INTRODUCTION}

Lotus, also known as water lily, is one of the top 10 traditional garden flowers and an economically valuable aquatic plant belonging to the genus Nelumbo, family Nelumbonaceae. In China, Nelumbo is the aquatic crop with the largest planting area and richest varieties. Lotus is rich in nutrition and widely used; every part of lotus is valuable. Lotus has great potential for use as food, ornamentals, medicine, and packaging (Zhou et al., 2002). In recent years, ornamental lotus has become popular in flower market consumption for its capability for beautifying cities, decking gardens, and dressing up courtyards. Therefore, broad market incentives exist for improving the genetic quality of the lotus and breeding new varieties with high ornamental value - e.g., multicolor, multi-flowering, long flowering period.

As a new and developing mutation breeding method, ion beam implantation is characterized by a low damage rate, high mutation rate, and wide mutation spectrum. Breeding technology using mutations induced by ion implantation has been applied in crops, ornamental plants, medicinal plants, and microorganisms (Wang et al., 2008). In 2005, new lotus mutants were generated using an ion implantation method. After 3 generations of observation, 6 lotus mutants with different floral designs, flower colors, and flowering periods have been identified. According to a popular theory, the mutation mechanism occurs through energy absorption, mass deposition, and the charging of energetic ions in plant seeds, which result in sequential bio-effects. To date, few investigations focused on the base sequence changes induced by low-energy ion implantation in higher plants.

In the current investigation, sequence-related amplified polymorphism (SRAP) DNA markers were used to amplify the genomic DNA of lotus mutants and controls. Then, SRAP fragments of the mutants and the controls in radiation-sensitive sites were cloned and sequenced for base sequence comparison.

\section{MATERIAL AND METHODS}

\section{Plant material}

$\mathrm{Fe}^{+}$ions were used to bombard the seeds of Baiyangdian red lotus under vacuum conditions at $2 \mathrm{MeV}$ with a fluence of $1 \times 10^{12} \mathrm{ions} / \mathrm{cm}^{2}$. The corresponding untreated species were regarded as controls. A total of 200 seeds, including half of the treated seeds and half of the controls, were soaked for approximately 1 month and then transplanted to tanks. All seeds used in the experiment were harvested from the same homozygote plant. The fine variable plants had been screened in 2006. The mutants - including lotus 1, lotus 2, lotus 3, lotus 4, lotus 5, and lotus 6 - and the controls (provided by Prof. Ying Su from Beijing Normal University) were chosen as the experimental materials in 2009 (Figure 1).

\section{DNA extraction}

Total genomic DNA was isolated from leaf tissues of the 6 mutants ( $\mathrm{F}_{3}$ generation) and the controls using an improved cetyltrimethylammonium bromide method according to a procedure described by Guo et al. (2004). The integrity of the purified genomic DNA was evaluated using $0.8 \%$ agarose gel electrophoresis. 


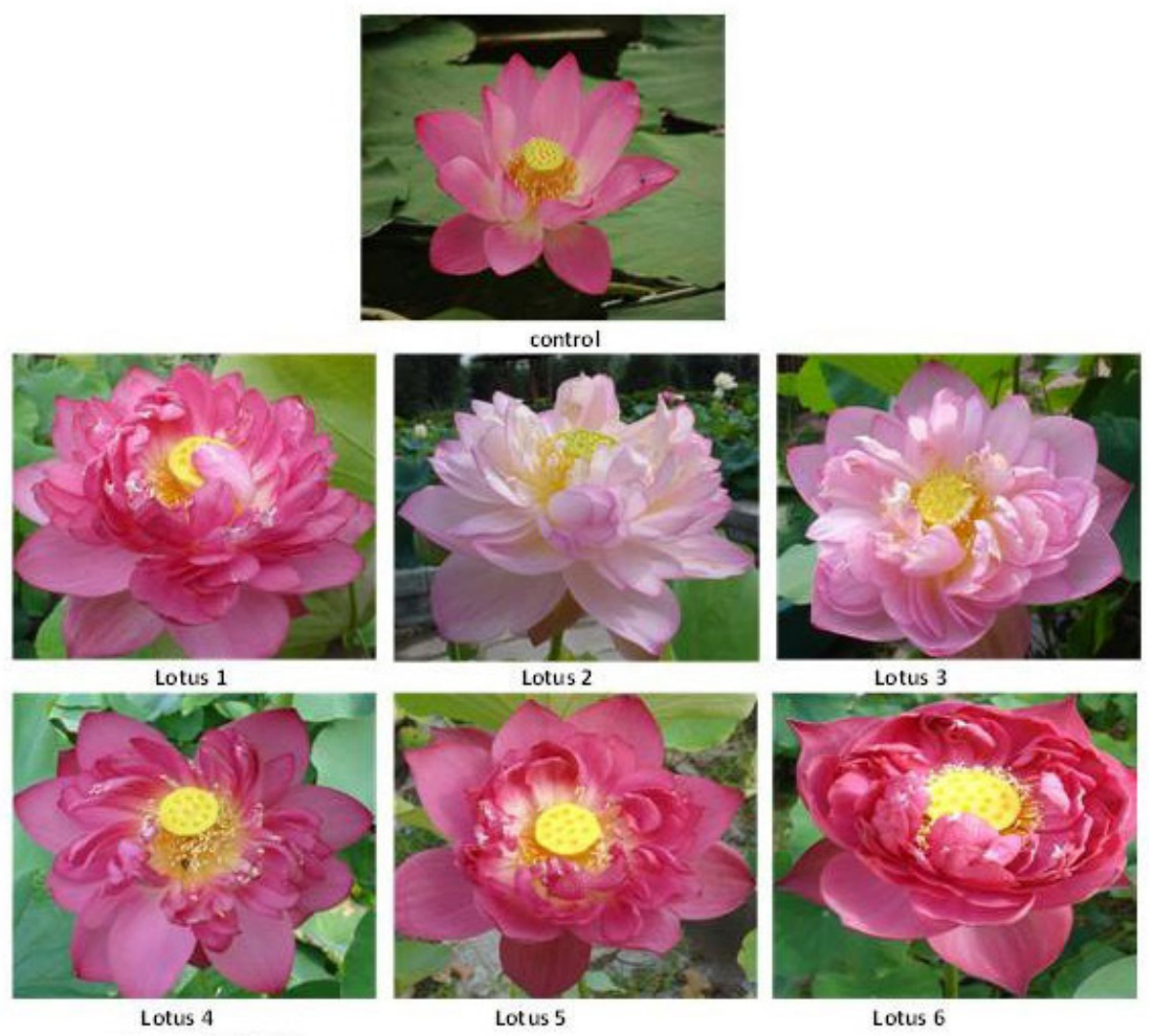

Figure 1. Materials used in this study. Lotus 1-6 = mutants 1-6.

\section{SRAP}

Polymerase chain reaction (PCR) primer pairs were synthesized by Shanghai Sangon (Shanghai, China) (Table 1) in a deoxyribonucleotide triphosphate mixture, $\mathrm{Mg}^{2+}$, and $\mathrm{Taq}$ DNA polymerase (TaKaRa, Dalian, China). PCR was carried out in a $25-\mu \mathrm{L}$ reaction mixture consisting of $2.5 \mu \mathrm{L}$ 10X PCR buffer $\left(\mathrm{Mg}^{2+}\right.$ free), $1.5 \mu \mathrm{L}$ (2.5 mM of each) deoxyribonucleotide triphosphate, $0.5 \mu \mathrm{L} 10 \mu \mathrm{M}$ primers, $1.8 \mu \mathrm{L} 25 \mathrm{mM} \mathrm{Mg}^{2+}, 1.5 \mathrm{U}$ Taq polymerase, and 40$80 \mathrm{ng}$ template DNA. Amplification was carried out with the following PCR program: 1 cycle at $94^{\circ} \mathrm{C}$ for $5 \mathrm{~min}, 5$ cycles at $94^{\circ} \mathrm{C}$ for $1 \mathrm{~min}, 35^{\circ} \mathrm{C}$ for $1 \mathrm{~min}$, and $72^{\circ} \mathrm{C}$ for $1 \mathrm{~min}$, and then 35 cycles for which the annealing temperature was increased to $50^{\circ} \mathrm{C}$. A final 8 -min extension at $75^{\circ} \mathrm{C}$ was also performed. PCR products were stored at $4^{\circ} \mathrm{C}$.

\section{Cloning and sequencing of special DNA fragments}

The putative special band amplified in the SRAP experiments was excised from $1.8 \%$ agarose gel using a UNIQ-10 DNA gel extraction kit (Shanghai Sangon). The purified target DNA fragments were cloned using pMD19-T vector (TaKaRa) according to manufacturer in- 
structions. The chimeric plasmid was transferred to Escherichia coli strain DH5 $\alpha$ via chemical transformation. Cloned fragments were sent to Shanghai Sangon for sequencing. Sequences were comparably analyzed with the DNAMAN software.

\section{RESULTS}

\section{Screening specific elements of 6 mutants using SRAP}

A total of 121 primer combinations were tested in 6 mutants and a control. Seven primer combinations generated clear bands with high polymorphism and good repeatability (Figure 2). The 7 primer combinations were me $1+\mathrm{em} 3$, me $1+\mathrm{em} 14$, me $9+\mathrm{em} 3$, me $8+$ em2, me6 + em1, me11 + em5, and me6 + em5 (for primer sequences, see Table 1). To avoid contamination and genetic heterogeneity, a negative PCR control with no template DNA was carried out simultaneously, and all experiments were repeated at least 3 times. The specific DNA fragments were cloned and sequenced.

A

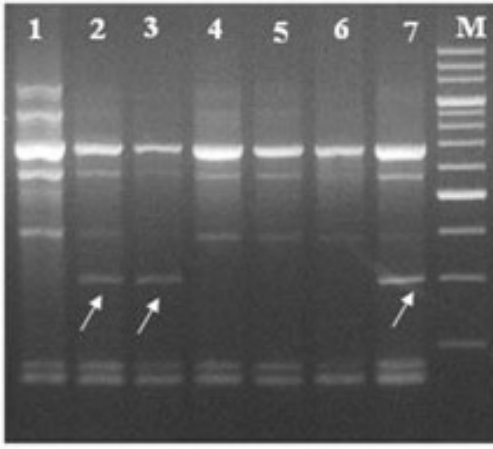

C

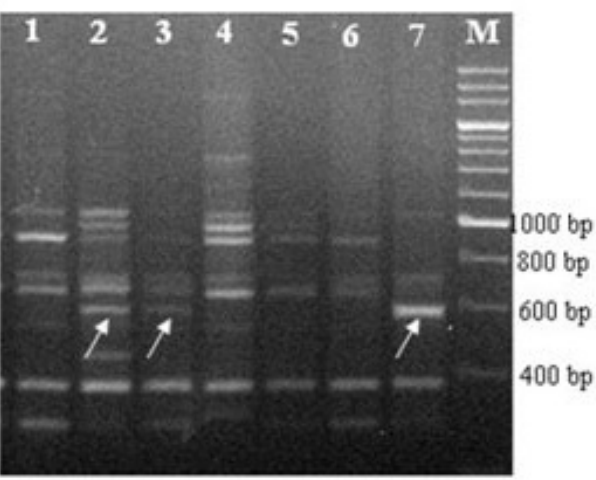

B
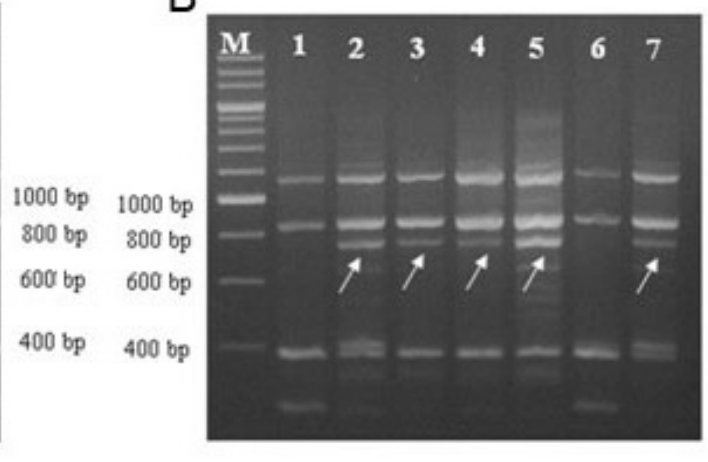

D

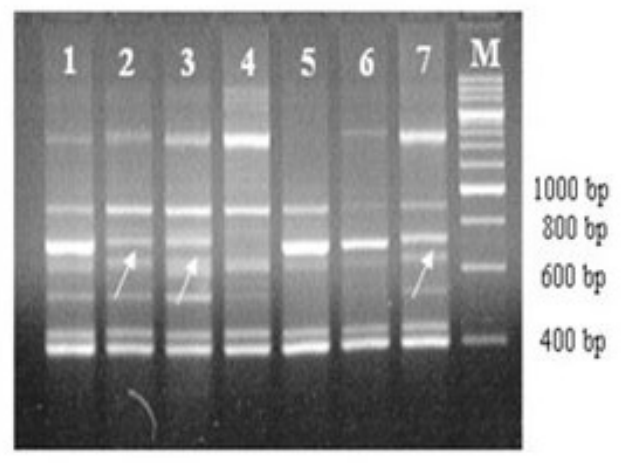

Figure 2. SRAP pattern of 6 mutants and the control. A. Amplified result of primer me $11+\mathrm{em} 5$. B. Amplified result of primer me $6+\mathrm{em} 5$. C. Amplified result of primer me $1+\mathrm{em} 6$. D. Amplified result of primer me + em8. Lane $1=$ Lotus 1 ; lane $2=$ lotus 2 ; lane $3=$ lotus 3 ; lane $4=$ lotus 4 ; lane $5=$ lotus 5 ; lane $6=$ lotus 6 ; lane 7 = control. Arrows show target bands cloned. 


\begin{tabular}{|c|c|c|c|}
\hline Forward primers & Sequences $\left(5^{\prime}-3^{\prime}\right)$ & Reverse primers & Sequences $\left(5^{\prime}-3^{\prime}\right)$ \\
\hline me1 & 5'-TGAGTCCAAACCGGATA-3' & em1 & 5'-GACTGCGTACGAATTAAT-3' \\
\hline me2 & 5'-TGAGTCCAAACCGGAGC-3' & em2 & 5'-GACTGCGTACGAATTTGC-3' \\
\hline me3 & 5'-TGAGTCCAAACCGGAAT-3' & em3 & 5'-GACTGCGTACGAATTGAC-3' \\
\hline me4 & 5'-TGAGTCCAAACCGGACC-3' & em5 & 5'-GACTGCGTACGAATTAAC-3' \\
\hline me5 & 5'-TGAGTCCAAACCGGAAG-3' & em6 & 5'-GACTGCGTACGAATTGCA-3' \\
\hline me6 & 5'-TGAGTCCAAACCGGTAA-3' & em7 & 5'-GACTGCGTACGAATTCAA-3' \\
\hline me7 & 5'-TGAGTCCAAACCGGTCC-3' & em8 & 5'-GACTGCGTACGAATTCTG-3' \\
\hline me8 & 5'-TGAGTCCAAACCGGTGC-3' & em9 & 5'-GACTGCGTACGAATTCGA-3' \\
\hline me9 & 5'-TGAGTCCAAACCGGATG-3' & em12 & 5'-GACTGCGTACGAATTATG-3' \\
\hline me10 & 5'-TGAGTCCAAACCGGGAT-3' & em14 & 5'-GACTGCGTACGAATTACG-3' \\
\hline me11 & 5'-TGAGTCCAAACCGGGCT-3' & $\mathrm{em} 15$ & 5'-GACTGCGTACGAATTGAT-3' \\
\hline
\end{tabular}

\section{Sequence analysis}

To reveal the changes in DNA base sequence induced by low-energy $\mathrm{Fe}^{+}$ion implantation in Baiyangdian red lotus, we compared the sequences of cloned SRAP fragments with their homologs using DNAMAN. The serial numbers of the mutation sites, types, and frequencies are listed in Tables 2-8. We detected 146 base changes in 15,317 bases and calculated a mutation frequency of $0.95 \%$. In the fragments specific for lotus 1 , lotus 2 , lotus 3 , lotus 4 , lotus 5 , and lotus 6 , base mutation frequencies of $1.41,0.92,0.53,0.78,1.50$, and $0.93 \%$ appeared, respectively.

\begin{tabular}{|c|c|c|c|c|c|c|c|c|}
\hline Mutants & 17 th site & 50th site & 174th site & 309th site & 488th site & 513th site & 585 th site & 646th site \\
\hline Control (754 bp) & $\mathrm{C}$ & $\mathrm{T}$ & A & A & A & G & $\mathrm{G}$ & $\mathrm{C}$ \\
\hline Lotus 1 & $\mathrm{~T}$ & $\mathrm{C}$ & A & $\mathrm{A}$ & $\mathrm{T}$ & A & G & $\mathrm{C}$ \\
\hline Lotus 3 & $\mathrm{~T}$ & $\mathrm{C}$ & A & A & $\mathrm{T}$ & A & G & C \\
\hline Lotus 4 & $\mathrm{~T}$ & C & A & G & $\mathrm{T}$ & A & $\mathrm{G}$ & C \\
\hline Lotus 6 & $\mathrm{~T}$ & C & G & A & $\mathrm{T}$ & A & A & $\mathrm{T}$ \\
\hline
\end{tabular}

\section{Table 3. Result of sequence alignment of primer me11 + em5.}

\begin{tabular}{lcc}
\hline Mutants & 491th site & 570th site \\
\hline Control & A & G \\
Lotus 2 & - & G \\
Lotus 3 & A & A \\
\hline
\end{tabular}

Table 4. Result of sequence alignment of primer me $6+$ em 1 .

\begin{tabular}{lc}
\hline Mutants & 475th site \\
\hline Control & $\mathrm{C}$ \\
Lotus 2 & $\mathrm{T}$ \\
Lotus 3 & $\mathrm{T}$ \\
\hline
\end{tabular}


Table 5. Result of sequence alignment of primer me $8+$ em 2 .

\begin{tabular}{lc}
\hline Mutants & 475th site \\
\hline Control & $\mathrm{C}$ \\
Lotus 2 & $\mathrm{T}$ \\
Lotus 3 & $\mathrm{T}$ \\
\hline
\end{tabular}

\begin{tabular}{|c|c|c|c|}
\hline Mutants & 43th site & 74th site & 79th site \\
\hline Control & A & A & $\mathrm{T}$ \\
\hline Lotus 2 & A & A & $\mathrm{T}$ \\
\hline Lotus 3 & $\mathrm{~A}$ & A & $\mathrm{T}$ \\
\hline Lotus 4 & G & G & $\mathrm{C}$ \\
\hline Lotus 5 & A & A & $\mathrm{T}$ \\
\hline
\end{tabular}

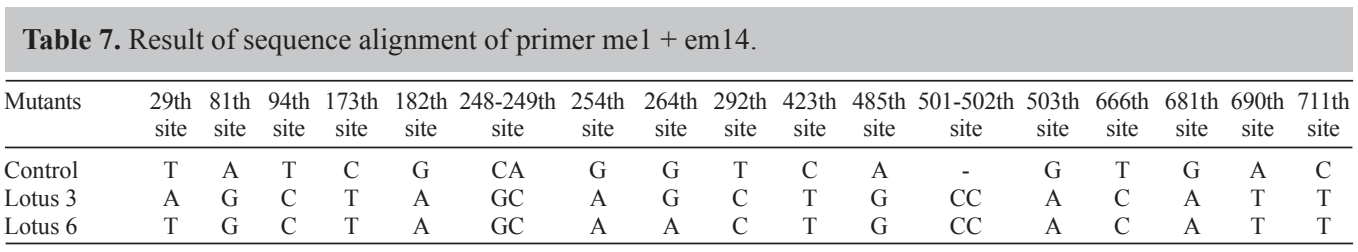

Table 8. Result of sequence alignment of primer me9 + em3.
\begin{tabular}{lcccccccccccccccc}
\hline Mutants & 109 & 177 & $183-197$ site & 219 & 234 & 397 & 579 & 618 & 726 & 732 & 780 & 849 & 897 & 901 & 922 & $929-930$ \\
& site & site & site & site & site & site & site & site & site & site & site & site & site & site & site \\
\hline Control & - & A & AGAAGAAGAAGAAGA & A & G & T & T & T & A & T & A & G & T & G & G & CC \\
Lotus 1 & A & G & - & G & A & C & T & C & C & C & A & G & C & A & C & - \\
Lotus 2 & A & A & - & G & A & T & A & C & C & T & A & A & T & A & C & - \\
Lotus 3 & A & A & AGAAGAAGAAGAAGA & A & G & T & T & T & A & T & A & G & T & G & G & CC \\
Lotus 4 & A & A & AGAAGAAGAAGAAGA & A & G & T & T & T & A & T & A & G & T & G & G & CC \\
Lotus 5 & A & A & - & G & A & T & T & C & C & T & T & G & T & A & C & - \\
\hline
\end{tabular}

\section{Analysis of base change types and characteristics of genomic DNA variations of mutants}

Compared with the control sequences, cloned fragments of the mutants showed 146 base changes. As shown in Table 9, the mutations included transitions, transversions, deletions, and insertions. The frequency of base substitutions (58.22\%) was higher than that of base deletions and base additions (41.78\%). Of the base substitutions, the frequency of base transitions (45.21\%) was 3.5 times of that of the base transversions $(13.01 \%)$. 


\begin{tabular}{lcr} 
Table 9. Types of mutation in 6 mutants induced by $\mathrm{Fe}^{+}$implantation. & Frequency $(\%)$ \\
\hline Types of mutation & Number of occurrence & 58.22 \\
\hline Base substitutions & 85 & 45.21 \\
Transition & 66 & 11.64 \\
T C & 17 & 10.27 \\
C T & 15 & 15.07 \\
G A & 22 & 8.22 \\
A G & 12 & 13.01 \\
Transversion & 19 & 1.37 \\
T A & 2 & 4.79 \\
A T & 7 & 2.05 \\
G C & 3 & 1.37 \\
C G & 2 & 3.42 \\
A C & 5 & 35.62 \\
Deletion & 52 & 21.23 \\
A & 31 & 10.27 \\
G & 15 & 4.12 \\
C & 6 & 6.16 \\
Insertion & 9 & 3.42 \\
+A & 5 & 2.74 \\
+C & 4 & 100 \\
Total & 146 & \\
\hline
\end{tabular}

The results showed that adenine, thymine, guanine, or cytosine could be replaced by other bases (see Table 9): adenine changes occurred 60 times (including 31 deletions and 5 insertions); guanine changes occurred 39 times (including 15 deletions); cytosine changes occurred 27 times (including 6 deletions and 4 insertions), and thymine changes occurred 19 times (no deletions and insertions). Therefore, adenine was the most sensitive to irradiation.

\section{DISCUSSION}

In recent years, the study of materials irradiated by ion implantation at the molecular level has increased. Molecular biology research on mutants induced by ion implantation, such as Medicago sativa L. (Chen et al., 2001), Cucumis melo L. (Chen et al., 2002), Buchloë dactyloides (Nutt.) Engelm. (Xiao et al., 2004), and Dahlia pinnata Cav. (Yu et al., 2008), have been carried out using RAPD markers. However, with the exception of studies in Nicotiana tabacum (Zhang et al., 1998) and Arabidopsis thaliana (Chang et al., 2003; Li et al., 2007), few investigations have focused on the base sequence changes induced by low-energy ion implantation in higher plants.

In this study, we identified 6 lotus mutants implanted with $\mathrm{Fe}^{+}$at a dose of $1 \times 10^{12}$ ions $/ \mathrm{cm}^{2}$. To reveal the molecular basis of low-energy $\mathrm{Fe}^{+}$-induced changes in genomic DNA, we subjected the mutants to SRAP and base sequence analysis. SRAP is new DNA marker invented by Li and Quiros (2001). SRAP has been used to construct genetic maps (Pan, 2005; Yu et al., 2007; Liu et al., 2011; Zhang et al., 2011) and perform genetic polymorphism research (Ferriol et al., 2004; Li et al., 2010; Wang et al., 2010; Yildiz et al., 2011). Of 121 primer combinations used in the present study for SRAP assay, 7 showed differences in SRAP patterns such as DNA fragment deletions or additions between the 6 mutants and the control plants. In the cloned DNA fragments from the mutants, an average mutation rate of one base change per 104.9 bases was detected. The base changes included transitions, transversions, deletions, and insertions. According to Yu (2000), the implanted ions punch atoms of molecules in double- 
stranded DNA chains and force them to shift from their original positions. The shifted atoms might interact with other elements in the DNA molecule and form additional new molecules, or they might shift completely and leave empty space at their original positions. The former leads to genetic effects such as base substitutions; the latter cause deletions and insertions of a single base or a small DNA fragment or even chromosome breakage and translocation. SRAP DNA marker can easily be used to detect these changes in DNA base sequences between the mutants induced by ion implantation and controls. SRAP analysis also showed that adenine was the most sensitive to irradiation. These results were the same as those reported by Zhang et al. (1998) and suggest that mutational "hotspots" induced by low-energy ion implantation probably exists in lotus.

\section{ACKNOWLEDGMENTS}

Research supported by the National Natural Science Funds of China (\#31000165).

\section{REFERENCES}

Chang F, Liu X, Li Y, Jia G, et al. (2003). Changes in DNA base sequences in the mutant of Arabidopsis thaliana induced by low-energy $\mathrm{N}^{+}$implantation. Sci. China C Life Sci. 46: 503-512.

Chen RL, Song DJ, Yu ZL, Li YF, et al. (2001). Study in mutation of alfalfa genome DNA due to low energy $\mathrm{N}^{+}$ implantation using RAPD. High Technol. Lett. 11: 12-19.

Chen RL, Song DJ, Li YF, Wu LJ, et al. (2002). Study in mutation of Muskmelon genome DNA due to low energy $\mathrm{N}^{+}$ implantation using RAPD. Acta Laser Biol. Sin. 11: 75-78.

Ferriol M, Picob de Cordova PF and Nuezf F (2004). Molecular diversity of a germplasm collection of squash (Cucurbita moschata) determined by SRAP and AFLP markers. Crop Sci. 44: 653-664.

Guo HB, Ke WD, Li SM and Peng J (2004). Cluster analysis of Nelumbo accessions based on RAPD markers. J. Plant Genet. Resour. 5: 328-332.

Li G and Quiros CF (2001). Sequence-related amplified polymorphism (SRAP), a new marker system based on a simple PCR reaction: its application to mapping and gene tagging in Brassica. Theor. Appl. Genet. 103: 455-461.

Li K, Nie YL, Zhang DZ, Zhang J, et al. (2007). AFLP analysis of Arabidopsis thaliana treated by low-energy ion beam. Plasma Sci. IEEE Trans. 35: 454-459.

Li L, Peng JY and Bai RX (2010). Analysis of the genetic relationships in chinese ziziphus with SRAP markers. Agric. Sci. China 9: 1278-1284.

Liu L, Ma X, Wei J, Qin J, et al. (2011). The first genetic linkage map of Luohanguo (Siraitia grosvenorii) based on ISSR and SRAP markers. Genome 54: 19-25.

Pan JS (2005). Construction of a genetic map with SRAP markers and localization of the gene responsible for the firstflower-node trait in cucumber (Cucumis sativus L.). Progr. Nat. Sci. 15: 407-413.

Wang Q, Pang CM, Zhang RB and Liu AC (2008). The research progress of ion beam bio-technology. Shanxi Forest Sci. Technol. 4: 71-75.

Wang YX, Sun XY, Tan BY, Zhang B, et al. (2010). A genetic linkage map of Populus adenopoda Maxim. x P. alba L. hybrid based on SSR and SRAP markers. Euphytica 173: 193-205.

Xiao ZA, Wu JY and Sun ZY (2004). Analysis of Buchlo(e) dactyloides mutants induced by implantation of low energy $\mathrm{C}^{+}$ion. J. Beijing Normal Univ. 40: 518-523.

Xie W, Zhang X, Cai H, Huang L, et al. (2011). Genetic maps of SSR and SRAP markers in diploid orchardgrass (Dactylis glomerata L.) using the pseudo-testcross strategy. Genome 54: 212-221.

Yildiz M, Ekbic E, Keles D, Sensoy S, et al. (2011). Use of ISSR, SRAP, and RAPD markers to assess genetic diversity in Turkish melons. Sci. Hortic. 130: 349-353.

Yu JW, Yu SX, Lu CR, Wang W, et al. (2007). High-density linkage map of cultivated allotetraploid cotton based on SSR, TRAP, SRAP and AFLP markers. J. Integr. Plant Biol. 49: 716-724.

Yu LX, Li WJ, Dong XC, Zhou LB, et al. (2008). RAPD analysis on dwarf mutant of Dahlia pinnata Cav induced by 80 $\mathrm{meV} / \mathrm{u}^{12} \mathrm{C}^{6+}$ ions. Nuclear Techniques 31: 830-833. 
Yu ZL (2000). Ion beam application in genetic modification. IEEE Trans. Plasma Sci. 28: 128-132.

Zhang GQ, Qi JM, Zhang XC, Fang PP, et al. (2011). A genetic linkage map of kenaf (Hibiscus cannabinus L.) based on SRAP, ISSR and RAPD markers. Agric. Sci. China 10: 1346-1353.

Zhang ZH, Du LQ, Li YX, Li HJ, et al. (1998). The variations of $\mathrm{M}_{1}$ to the seeds of tobacco implanted with ion bean. Acta Biophys. Sin. 14: 762-766.

Zhou MQ, He JJ and Hu ZL (2002). Considerations and suggestions for lotus industry developing in Hubei. Amino Acids Biotic Resour. 24: 22-24. 